\title{
A DANÇA AFRO-BRASILEIRA EM LONDRINA - PARANÁ
}

\author{
Silvia Pavesi Sborquia \\ Universidade Estadual de Londrina, Londrina, Paraná, Brasil \\ André Dalben \\ Universidade Estadual de Londrina, Londrina, Paraná, Brasil
}

\begin{abstract}
Resumo
Com base em um contexto problemático pautado pela necessidade de estudos que permitam explorar e conhecer a diversidade étnico-racial presente nas mais diversas localidades do país, esta pesquisa teve como objetivo geral analisar o significado das manifestações dançantes da cultura afro-brasileira presente nas produções do Grupo de Dança Cristal em Londrina, no Paraná. Esta foi uma investigação exploratória de caráter qualitativo, que teve como procedimento de coleta de dados a entrevista semiestruturada. Concluiu-se que as ações promovidas pelo Grupo de Dança Cristal possibilitam uma permanente reconstrução da cultura afrobrasileira, em uma postura de resistência e de valorização da diferença que se apoia em um projeto de sociedade plural e democrática.
\end{abstract}

Palavras-chave: Cultura. Manifestações Afro-Brasileiras. Dança.

\section{Introdução e justificativa: história e cultura afro-brasileira}

A modernidade e o escravismo colonial são uma engrenagem complexa. Por conseguinte, para discutir a cultura afro-brasileira, é necessário repensar toda a história da humanidade, uma vez que a escrita histórica prezou, por muito tempo, apenas por determinados grupos sociais. Por isso, para elucidar o conhecimento e a compreensão das diversas sociedades humanas, em seus próprios termos, é necessário que haja questionamentos dos valores e das convicções de nossa sociedade por meio da crítica ao etnocentrismo, à intolerância e à negação da diferença.

A Lei $\mathrm{n}^{\mathrm{o}} 10.639$, de 9 de janeiro de 2003, em seu art. 26, tornou obrigatório o ensino de História e Cultura Afro-Brasileira, estabelecendo um ponto de partida para o reconhecimento da importância da cultura africana na construção das ressignificações da cultura brasileira. Por conseguinte, representa também o caminho para a valorização da participação da população afrodescendente na história brasileira. Os últimos debates, decorrentes da formulação da Base Nacional Comum Curricular (BNCC) proposta pelo Ministério da Educação ${ }^{1}$, apontam para a afirmação da crítica à perspectiva eurocêntrica da História, com a consolidação da introdução

\footnotetext{
${ }^{1}$ Atualmente, o documento da BNCC encontra-se na fase de segunda versão, após ter passado por consulta pública. Entende-se que a presente pesquisa pode trazer contribuições para o debate em curso, especialmente no que se refere ao componente curricular da Educação Física.
} 
da História da África nos currículos escolares, de modo que possibilitem ao aluno a compreensão das alteridades presentes na formação da sociedade brasileira e o respeito as suas pluralidades étnico-raciais e culturais (BRASIL, 2016).

No que diz respeito especificamente à dança, a Educação Física ${ }^{2}$ tem procurado reconhecer a importância das danças étnicas na construção de interações referenciadas na solidariedade, na justiça, na equidade e no respeito às diferenças (BRASIL, 2016). Tal reconhecimento está de acordo com a legislação sobre o ensino da cultura afro-brasileira, assim como com as Diretrizes Nacionais para a Educação em Direitos Humanos, que estabelecem, desde 2012, o reconhecimento e a valorização das diferenças e das diversidades de nossa sociedade (BRASIL, 2003, 2012). É certo que, no processo de adaptação das normas legais ao cotidiano escolar, há um longo percurso a ser trilhado. No entanto, não podemos deixar de considerar tais diretrizes como um avanço para a conquista de uma educação plural e que respeite a diversidade étnica da população brasileira (CORSINO; CONCEIÇÃO, 2016).

No âmbito da formação superior em Educação Física, seja na modalidade licenciatura, seja na de bacharelado, as diretrizes instituídas determinam que os conhecimentos ensinados devem estar orientados por valores sociais, morais, éticos e estéticos próprios de uma sociedade plural e democrática (BRASIL, 2004). Nesse sentido, para a formação de profissionais que apresentem uma conduta que valorize o diálogo e o respeito pela diversidade das manifestações corporais, compreende-se como indispensável o trabalho pedagógico de práticas corporais constitutivas da cultura e da tradição afro-brasileira no ensino superior.

Em consonância com as diretrizes referentes à Educação Física de nível superior, observa-se um processo de acumulação de novos conhecimentos acadêmicos sobre as práticas corporais afro-brasileiras, conhecimentos estes formulados nos programas de pós-graduação em Educação Física no decorrer das últimas duas décadas. De modo geral, é possível identificar que as pesquisas acadêmicas desenvolvidas nessa temática se concentram no estudo das práticas corporais afro-brasileiras no contexto escolar ${ }^{3}$ e das práticas corporais de comunidades quilombolas no contexto do lazer ${ }^{4}$. De tradição mais antiga e que extrapolam o campo acadêmico da Educação Física, são as pesquisas dedicadas ao estudo das lutas e danças afrobrasileiras, sobretudo no que diz respeito à capoeira e ao samba.

Em conjunto, toda essa profícua produção acadêmica tem conferido respaldo científico e social para as novas diretrizes de ensino estabelecidas nos últimos anos, assim como as que se encontram atualmente em debate. Representam, sobretudo, um grande avanço para a Educação Física brasileira se afirmar como um campo de intervenção plural e democrático. É nesse sentido que se insere o presente artigo, ao reconhecer a necessidade de fomentar os debates referentes às práticas corporais afro-brasileiras por meio de investigações que explorem a diversidade étnica presente nas mais diversas localidades do país.

\section{Problema e objetivo: práticas corporais afro-brasileiras em Londrina (PR)}

A respeito da presença negra na cidade de Londrina, o Laboratório de Cultura e Estudos Afro-Brasileiros (LEAFRO), do Departamento de Ciências Sociais da Universidade Estadual de Londrina, tem divulgado nos últimos anos a trajetória e as lutas da população negra

\footnotetext{
${ }^{2} \mathrm{O}$ componente curricular Arte estabelece a dança como uma de suas quatro linguagens e a concebe em suas diferentes matrizes estéticas e culturais (BRASIL, 2016).

${ }^{3}$ A título de exemplo, conferir a pesquisa coordenada pelo Prof. Dr. Luiz Gonçalves Junior (UFSCar), sob o título "A motricidade humana em diferentes culturas: educação para a paz através da diversidade", e suas respectivas publicações, assim como a publicação organizada por Corsino e Conceição (2016).

${ }^{4}$ A título de exemplo, conferir as pesquisas coordenadas pela Profa. Dra. Larissa Michelle Lara (UEM), sob o título "Políticas públicas de esporte/lazer em comunidades quilombolas no Paraná", e a pesquisa coordenada pela Profa. Dra. Ana Márcia Silva (UFG), sob o título "Manifestações da cultura corporal em comunidades remanescentes de quilombos: um acervo inicial no estado de Goiás" e suas respectivas publicações.
} 
no processo de nascimento, desenvolvimento e consolidação da cidade. Segundo pesquisas de Silva $(2011,2014)$, a população negra esteve presente desde os primeiros anos do processo de colonização do norte do Paraná, muito embora a história oficial de Londrina não a mencione. Durante muito tempo, a história da cidade de Londrina foi contada unicamente a partir da presença dos imigrantes alemães, japoneses, italianos e, sobretudo, ingleses, sendo a participação da população negra esquecida, subestimada ou mesmo negada.

Processo semelhante ao ocorrido na história oficial do estado do Paraná, na tentativa de afirmar a sua formação cultural como essencialmente europeia. A pesquisa desenvolvida pelo Grupo de Trabalho Clóvis Moura, no entanto, revisou essa percepção historicamente construída e levantou que, na primeira metade do século XIX, o número estimado de escravos negros chegou a representar $40 \%$ da população da província do Paraná (emancipada politicamente em 1953). No mapeamento realizado pelo grupo, foram identificadas cerca de 90 comunidades quilombolas ainda existentes no território do Paraná, sendo a população do estado composta por um quarto de negros e pardos, segundo dados do IBGE (PNAD, 2007). Revelase, assim, como o estado mais negro da região Sul do Brasil (GOMES JUNIOR; SILVA; COSTA, 2008).

Conforme analisado pelos estudos desenvolvidos pelo Grupo de Pesquisa Corpo e Ludicidade da Universidade Estadual de Maringá (UEM), a identificação e o estudo das práticas corporais de matriz afro-brasileiras são de grande relevância para a implementação de políticas de lazer que tenham por compromisso o resgate e a reconstrução da memória coletiva das comunidades quilombolas existentes no Paraná (LARA, 2012; LARA; PIMENTEL, 2013). Nesse sentido, destacam-se as ações de intervenção social realizadas desde 2007 pela Companhia de Música e Dança Afro Kundun Balê junto à comunidade quilombola Invernada Paiol de Telha, assentamento localizado no município de Guarapuava (PR). De acordo com Gonçalves (2012), a intervenção social empreendida pelo grupo de dança se estabelece como fundamental para o resgate da memória e da identidade quilombola pela comunidade. É por meio de uma experiência corporal vivida através da dança, de seus gestos, ritmos, músicas e comportamentos que os integrantes do grupo apreendem e disseminam a cultura afro-brasileira.

Apesar de Londrina não contar com comunidades quilombolas no seu entorno, a presença negra se faz efetiva na cidade desde sua fundação, em 1934, tendo se intensificando a partir da década de 1950, com a migração de famílias afrodescendentes dos estados de Minas Gerais, da Bahia, de Sergipe e Pernambuco (PANTA, 2014). De acordo com pesquisa realizada por Silva (2014), a população negra em Londrina representa atualmente um quarto do seu total de habitantes e se concentra, em sua maioria, em bairros periféricos da cidade, onde não encontra pleno acesso a direitos básicos e infraestruturas sociais e urbanas.

Como ação coletiva organizada, a comunidade negra de Londrina tem procurado estabelecer instrumentos de promoção social desde os primeiros anos de fundação da cidade (SILVA, 2011). Em nível nacional, segundo Domingues (2007), a população negra conseguiu se organizar em uma militância com um maior grau de articulação política principalmente a partir da década de 1980, junto ao processo de redemocratização brasileiro. Foi nessa década que a comunidade negra londrinense criou o Grupo União e Consciência Negra e realizou a primeira edição da Semana Zumbi dos Palmares (ALMEIDA, 2004). As ações do movimento se consolidaram, nas décadas seguintes, com projetos como Resgate da Raça Negra, Tradições e Identidade, que ofereciam oficinas itinerantes de percussão, teatro, cantos africanos, capoeira, afoxé, dança afro-brasileira etc., com o objetivo principal de conservar e valorizar a cultura afro-brasileira (LANZA et al, 2013; SILVA; PACHECO, 2014). Atualmente, Londrina conta apenas com um grupo de dança afro-brasileira registrado na Secretaria de Cultura do município. Trata-se do Grupo de Dança Cristal, o qual se encontra inserido no Centro de Produtores Independentes de Arte e Cultura (CEPIAC). 
Ao estabelecer que o presente estudo vem corroborar a temática afro-brasileira a partir da análise e interpretação de uma cultura local, se concebeu como objetivo geral analisar o significado das manifestações dançantes da cultura afro-brasileira presente nas produções da cidade de Londrina, mais especificamente do Grupo de Dança Cristal. Como objetivos específicos foram definidos: a) identificar a tradição do Grupo de Dança Cristal; b) verificar a relação do grupo com a sociedade na qual está inserido.

\section{Metodologia}

A pesquisa que resultou no presente artigo integra um projeto maior de investigação que se preocupou com a compreensão dos significados culturais da dança na cidade de Londrina, aprovado pelo Comitê de Ética por meio do Parecer n. ${ }^{\circ}$ 01888712.5.0000.5231. Em seu primeiro momento, a pesquisa focou no mapeamento dos grupos de dança organizados em Londrina por meio de levantamento documental do conjunto de matérias publicadas no jornal Folha de Londrina sobre dança, no período de 1980 a 2010. O procedimento de coleta de dados foi realizado através de fotografia e digitalização das imagens em um acervo de 10.800 edições do jornal Folha de Londrina, disponível no Centro de Documentação e Pesquisa Histórica da Universidade Estadual de Londrina.

A análise documental se estruturou a partir da análise de conteúdo (BARDIN, 1977), tendo como categorias a priori: a) grupos existentes; b) grupos visitantes e espetáculos; c) estilo de dança apresentado pelo grupo; d) como a dança foi divulgada no jornal Folha de Londrina. De modo geral, essa etapa mais ampla da pesquisa possibilitou a identificação de uma grande diversidade de grupos de dança na cidade, com os seguintes estilos e tradições: balé clássico, dança flamenca, dança de rua, dança de salão, dança árabe, dança japonesa e dança afro-brasileira (CAMARGO; SBORQUIA, 2013).

Entre as tradições de dança levantadas nessa etapa da pesquisa, a dança afro-brasileira foi eleita como principal objeto de estudo para o desenvolvimento da investigação que resultou no presente artigo. Em consulta ao jornal Folha de Londrina, foi identificado somente um grupo de dança afro-brasileiro, o Grupo de Dança Cristal, localizado em duas reportagens nos anos de 2008 e 2010. Após a identificação nas matérias dos jornais, buscaram-se informações da Secretaria de Cultura do município sobre a existência de grupos de dança, sendo localizado o registro do Grupo de Dança Cristal como único grupo de dança afro-brasileira da cidade (SOUSA; SBORQUIA, 2014).

No segundo momento da pesquisa, optou-se pelo procedimento de coleta de dados a partir de entrevista semiestruturada com a coordenadora do Grupo de Dança Cristal (TRIVIÑOS, 1997). A entrevista seguiu os procedimentos da análise de conteúdo temática. Foram estabelecidas categorias a priori elaboradas a partir da fundamentação teórica investigada: 1) a tradição do grupo; 2) transmissão cultural da dança; 3 ) sentidos e significados da dança.

O tratamento dos dados coletados seguiu um processo de interpretação, o qual implica um constante movimento entre as partes e o todo. "A importância do processo hermenêutico é sua ênfase na necessidade de contextualizar o significado da expressão humana e de não divorciá-lo desse contexto" (SANCHES GAMBOA, 2000, p. 28).

\section{Resultados e discussão}

De modo a elucidar a tradição do grupo, indagamos como foi o início do Centro de Produtores Independentes de Arte e Cultura. A idealização do projeto teve início no primeiro Encontro Nacional de Mulheres Negras em 1988, em Valença, no Rio de Janeiro. A coordenadora relata que, à época, estava envolvida com o Movimento de União e Consciência Negra (MUCON) em Londrina, no qual desenvolvia um trabalho de resgate dos costumes tradicio- 
nais da cultura afro-brasileira. Relata, também, que tinha uma ligação no trabalho com Dona Vilma, importante figura do movimento negro nacional e em Londrina (LANZA et al., 2013). O envolvimento com a dança surgiu no primeiro Encontro Nacional de Mulheres Negras; posteriormente, organizou uma apresentação na comemoração do centenário da abolição da escravatura, em 1988 - então, teve início um grupo de teatro, canto e dança, o Momulu de Aluê. É importante ressaltar que a idealização do Grupo de Dança Cristal se deu junto ao movimento negro organizado na década de 1980, seja em nível municipal, seja em nível nacional, sendo o Momulu de Aluê sua primeira expressão. A sua idealização antecedeu a própria criação do CEPIAC, a qual se efetivou em 1999 a partir da necessidade de ocupação de horas ociosas de jovens e adolescentes no bairro em seu entorno.

O CEPIAC não apresenta a pretensão do ensino formal de dança, música ou teatro. Começou com um pequeno grupo de pessoas que decidiu se unir para trocar conhecimentos. No início, eram apenas algumas mulheres que se reuniam para ensinar e aprender tricô, crochê e corte e costura. Mais tarde, o projeto passou a envolver também crianças da comunidade. "Algumas crianças vieram me dizer que queriam fazer alguma coisa no tempo vago, então começamos a fazer brincadeiras na praça". 5 Com o aumento do número de participantes, surgiu a necessidade de um espaço para desenvolver outras atividades. $\mathrm{O}$ envolvimento da coordenadora do centro com o movimento negro foi fundamental para a inserção do trabalho com cultura de matriz africana entre os projetos desenvolvidos pelo CEPIAC. Em 2002, a Secretaria da Cultura cedeu o espaço de um antigo posto de saúde no conjunto João Paz, um dos cinco conjuntos de Londrina na zona norte, para a realização das atividades do CEPIAC.

Desde então, o número de atividades e participantes continuou a crescer. No CEPIAC, todos são voluntários, alunos e professores de educação não formal. "Aqui, quem sabe ensina para quem não sabe." Hoje o CEPIAC é reconhecido como centro de convivência cultural comunitária, sendo certificado pelo Ministério da Cultura como ponto de cultura ${ }^{6}$. O CEPIAC investe na formação de multiplicadores comunitários de cultura por meio da realização de projetos de arte-educação que procuram resgatar e preservar a cultura afro-brasileira. Nesse sentido, é possível afirmar que o espaço vem se consolidando como instrumento de democratização cultural no município de Londrina. Trata-se de um trabalho que tem contribuído diretamente para a construção da cidadania de jovens e adolescentes. O principal trabalho do CEPIAC são as oficinas de dança, canto e percussão. Segundo ela, a questão da identidade afrobrasileira é de grande relevância para o grupo:

você sabe se uma pessoa tem sangue negro, não é pela cor dela, é quando ela escuta os tambores e o ombro começa a mexer. Então, é sinal de que ela está entrando no tambor e, quando ela entra, pode esquecer que ela não sai mais.

Tais afirmações entram em consonância com os dizeres de Paixão (2009), pois a compreensão sobre a produção do conhecimento em dança a partir de estudos sobre as matrizes culturais africanas na dança negra contemporânea requer um entendimento que a cultura brasileira tem sido forjada a partir do encontro das tradições de povos de diferentes origens étnicas, sendo esses elementos basilares e constitutivos da cultura brasileira. Destaca as contribuições de povos indígenas, africanos e europeus. Isto denota que as diferentes culturas têm de ser compreendidas em sua originalidade porque envolvem linguagens, valores, símbolos e estilos de comportamentos diferentes. A tradição do grupo revelou que sua identidade está especialmente marcada pelos saberes e fazeres da cultura afro-brasileira e que a identidade

5 Todas as falas transcritas neste artigo advêm da entrevista com a coordenadora do Grupo de Dança Cristal. 6 A respeito da Política Nacional de Cultura Viva, criada em 2004 e responsável pelos pontos de cultura, consultar Turino (2010). 
trabalhada pelo grupo não opera pelo conceito de raça ${ }^{7}$. Para além da significação cultural, o grupo apresentou questões relativas à diferença que foram determinadas pelos processos históricos, pelas ideologias e pelas relações de poder que mobilizaram processos políticos e sociais.

Trabalhamos com cultura de matriz africana, pela necessidade de resgate e preservação da cultura afro-brasileira porque ela é importante na comunidade, como identidade e, principalmente, porque a maioria não tem informação de que ela exista.

Decorre daí que os caminhos da produção cultural de um povo foram, muitas vezes, obstruídos "enquanto memória negada ou recalcada, enquanto memória distorcida ou mesmo completamente deturpada por aqueles que têm a força para se impor. A história cultural de um povo, na maioria dos casos, fica sendo a história das dimensões hegemônicas dessa cultura" (LARA,1990, p.104). O mundo da cultura e seu movimento ao ser confrontado com outros universos pressupõem interesses diversos postos numa relação de alteridade (o eu e o outro em relação) mais que de diversidade (o eu e o outro). Por conseguinte, os processos de manipulação da realidade se dão segundo diferentes formas de percepção e conhecimento. O contato entre povos diferentes e culturas diversas coloca em questão um espaço de encontro, confronto e de conflito, marcado pelo diverso, pelo diferente (GUSMÃO, 1997).

A origem social do CEPIAC surge da necessidade da manutenção da cultura popular, bem como da preservação da tradição afro-brasileira. Percebe-se que o grupo rompe com modelos hegemônicos de cultura e assume uma postura de resistência ao assumir a cultura popular como parte integrante da dialética social e antítese da cultura erudita.

Somos um grupo de pessoas encantadas pela cultura brasileira. Encontramos nela um meio de nos comunicar, de nos posicionarmos, homenageando ou tecendo críticas construtivas sobre fatos da nossa sociedade e principalmente transmitir aprendizados da cultura afro-brasileira. [...] Não é fácil, porque estamos no Sul do Brasil, estamos num bairro de periferia, onde o rap e o funk dominam. E para mantermos e valorizarmos a nossa cultura, não basta dizer como somos e o que temos hoje, e sim dizer quem somos. Foi uma escolha, por acreditarmos que um país que não tem cultura não tem memória, não tem história, e que acaba consumindo outras culturas, sem referência, sem identidade definida. Não preservando nossa história e costumes, somos qualquer coisa, menos o povo brasileiro.

A coordenadora do grupo revela a compreensão de que o estado do Paraná mantém particularidades sócio-históricas que dificultam o desenvolvimento de um projeto de dança afrobrasileira e que essa dificuldade se relaciona ainda com questões trazidas pela mídia e pela própria comunidade local. Quando indagamos sobre qual espaço do grupo e sua relação com a sociedade, a líder do Grupo de Dança Cristal relata que, na periferia da cidade, o medo e a violência fazem parte do dia a dia não apenas dos adultos, mas também das crianças e adolescentes. Apesar de algumas dificuldades que enfrenta, o CEPIAC conta hoje com cerca de 500 pessoas cadastradas. "A sede está localizada atrás de um bar e muitos homens vêm beber e jogar sinuca, então, quando as meninas chegam, muitas vezes, escutam comentários como: 'vai começar a macumba'." Por outro lado, a falta de reconhecimento por parte da comunidade local é compensada pelo estabelecimento de relações com políticas públicas de fomento da cultura e da arte, tanto em nível municipal quanto nacional, assegurando o trabalho do grupo.

7 Conceito antropológico sustentado pelo determinismo biológico (GUIMARÃES, 1999). 
Nos 10 anos de existência, ganhamos quatro prêmios do Ministério da Cultura, um prêmio da Funarte em dinheiro pelo trabalho que desenvolvemos, e tivemos dois projetos aprovados e executados pelo Ministério da Cultua e três projetos aprovados e executados pelo PROMIC - Programa Municipal de Incentivo à Cultura, o último realizado em 2012.

Outra questão abordada foram os sentidos e significados da dança para o grupo. Cabe ressaltar que, para que as práticas sociais sejam cultura, necessariamente, é preciso que elas tenham significado para aqueles que a realizam. Toma-se por base a compreensão de que cultura é o conjunto de todas as construções simbólicas realizadas e mediadas pelos seres humanos que determinam a forma da sociedade (GEERTZ, 1989). O presente trabalho de pesquisa considerou que a relação canto e dança é visceral na produção cultural das comunidades negras por meio dos chamados batuques. Deste modo, foi perguntado o que a dança significa para o grupo.

[...] a dança consegue romper paradigmas sociais, gerar transformações no cotidiano do jovem, na família e na comunidade. Ela é um veículo importante de comunicação e expressão dos nossos sentimentos [...] porque a dança, além de ser leve, ela chama a fala, o corpo chega primeiro do que o texto.

Os dados possibilitaram criar um mapeamento simbólico da elaboração do conhecimento e da organização e expressão dos sentimentos e paixões do grupo investigado. Para o grupo, a dança constitui-se como um componente simbólico da ação humana, como elemento constitutivo da vida e parte integrante dela, pois está incorporada nos gestos. Segundo Durham (1984), a cultura tem certo caráter lúdico, como se os homens, tendo desenvolvido sua capacidade simbólica em função de e para sua prática social, brincassem com ela na elaboração de estruturas infinitamente complicadas e, por isso, aparentemente e esteticamente satisfatórias.

Sobre as danças trabalhadas pelo Grupo de Dança Cristal, sua coordenadora afirma:

Trabalhamos com a cultura popular e a cultura tradicional. Na França, algumas pessoas veem o popular como pequeno em relação à cultura tradicional. A cultura tradicional é a herança de um povo, muito rica para ser popular. Então, preservamos nossa identidade. Trabalhamos com vários ritmos brasileiros como samba de roda, maracatu, baião, jongo, a ciranda, o coco.

No campo teórico e político dos Estudos Culturais, a cultura é entendida como espaço de luta, ou seja, qualquer transmissão cultural é sempre travada, disputada, conquistada e transformada pelos grupos envolvidos; uma construção que ocorre nas relações entre os diversos grupos sociais e entre seus membros (HALL, 2003). Deste modo, o estudo sobre a cultura popular ou suas transformações requer a análise sobre as mudanças no equilíbrio e nas relações das forças sociais em torno da cultura dos trabalhadores e dos pobres, nas tradições e formas de vida das classes populares (HALL, 2003). No debate cultural, o popular é entendido como categoria de oposição àquilo que é erudito (tradicional), o que pertence às elites. $\mathrm{Na}$ tradição segregacionista da sociedade capitalista, o que é domínio do povo não pode ser um conteúdo das classes dominantes.

A respeito da origem destas danças ou onde o grupo busca suas fontes de estudo, há um consenso de que: 
O trabalho cultural que desenvolvemos vem da transmissão oral dos nossos ancestrais, também chamada de cultura Griô, que consiste no aprendizado dos Mestres com os Mestres, que aprenderam com seus pais, que aprenderam com seus avós, comunicação milenar. Porque hoje o que encontramos nos livros, na internet, são relatos desta mesma fonte, porém sem o calor do contato humano, a essência do que se está transmitindo. Procuramos sempre um contato com aqueles que preservam e transmitem a tradição. A maioria das danças faz reverências aos elementos da natureza.

Segundo Paixão (2009), a ideia de transmitir os conhecimentos de uma geração à outra, de pai para filho, promove uma interação, uma rede, uma trama construída entre corpo, arte e cultura. Neste sentido, o conhecimento que se pretende manter vivo depende da transmissão cultural e necessita da capacidade de criatividade e inventividade dos seres humanos. Assim sendo, a oralidade se constitui numa tradição predominante junto ao seio das comunidades afro-brasileiras, sendo fundamental para a construção de sua identidade étnica.

A base da informação não encontrava nos livros, por isso busquei na memória do meu avô, tataravô, nas rodas de prosa da época. E junto com esse material dos terreiros, das histórias das rodas de prosa, de onde vem o Boi da Cara Preta, aí eu me encontrei com pessoas que me ensinavam "passos de jongo", coco, maracatu e outros tantos movimentos que contam a história dos ancestrais.

A análise dos dados permitiu inferir que a opção pela dança popular e tradicional possibilita ao grupo uma liberdade de criação de coreografias que culminam nos espetáculos. $\mathrm{O}$ grupo busca interpretar situações do cotidiano e os sentidos e significados que representam e refletem a cultura afro-brasileira:

[...] cada montagem tem uma estória, e todas com sua importância para nós. Flores e cantigas foi uma homenagem para todas as mulheres que lidam na lavoura, então são várias cantigas que elas cantavam enquanto batiam o feijão, colhiam o café, cortavam a cana. As músicas e danças falam sobre isso, sobre o trabalho na lavoura.

Com base em Chauí (1995) e Canclini (2000), é possível analisar que a cultura popular manifestada pelo coletivo em sua transmissão de geração a geração é dinâmica e, ao mesmo tempo, ressignificada ao longo do tempo. É possível inferir que as montagens coreográficas trazem como temas as vivências na agricultura, buscando a memória dos antepassados por meio dos gestos corporais que se cristalizam nas coreografias. Como mostra Santos (2002), a dança tem tido o poder de reforçar a importância do corpo como instrumento e símbolo do poder, como tem, também, revigorado um conjunto de valores e crenças. Em conjunto com o resgate de uma memória coletiva, é possível identificar também o processo de criação das coreografias que se preocupam em apresentar a realidade vivida dos membros do grupo.

A escolha do tema é do grupo e tudo é realizado de forma compartilhada. A gente senta e conversa até chegar a um consenso. Em 2008, As mulheres catadoras; montamos em 2003 o Contraponto; 2004, Sambateado; 2005, Alma brasileira; 2006, Cantos brasileiros e outros, todos com foco social, de contestação e alerta.

A realidade vivida implica um fazer e refazer constantes, via processos culturais que, no dizer de Lara (1990), produzem e veiculam projetos de vida humana, com propostas tidas como válidas e, como tais, transmitidas. Daí que o processo de se ver e ver aos outros só pode 
ocorrer em contextos históricos concretos em termos do conhecimento que se constrói com a vida sendo vivida. Os dados revelaram que a cultura transcendeu a formação simbólica, porque constituiu-se como mediação e, através dessa mediação, se fez política em seu sentido mais amplo. Ou seja, a criação das coreografias se materializa por processo de diálogo que elucida a realidade vivida pelos componentes do grupo e as tradições afro-brasileiras, estabelecendo um sentimento de pertença. As produções coreográficas do grupo asseguram, assim, uma mediação com a sociedade pautada em contestações e alertas sobre as lutas históricas das populações afrodescendentes. Ressalta-se que a mediação estabelecida pelo grupo com a sociedade por meio da dança permite uma ciência compreensiva, pois ela é tudo o que medeia a relação entre diferentes grupos sociais, sendo capaz de criar pontes entre os sujeitos, formando o diálogo e, por isso, pode ir além das discussões políticas.

\title{
Conclusão
}

O presente trabalho trilhou um percurso em busca da compreensão de um processo em contínua construção, desconstrução e reconstrução de um significado histórico e dinâmico da cultura afro-brasileira que revelou um jogo de relações sociais mostrando uma cultura que não é, mas, que a cada momento, está sendo. Denota-se a caracterização de um processo de interação, disputa e de transformação das diferentes culturas presentes na sociedade brasileira. Vale ressaltar que o posicionamento que se deseja requer um diálogo que estabeleça as interrelações entre a igualdade e a diferença, o universalismo e o relativismo e a globalização e a pluralidade cultural. Por conseguinte, é necessário o reconhecimento do outro para o diálogo entre diferentes grupos sociais e culturais na constituição de uma sociedade democrática.

Como afirmado inicialmente, para conceber a cultura afro-brasileira em suas singularidades, é importante pensar a história da humanidade por meio da crítica ao etnocentrismo e à negação da diferença. Tona-se, assim, necessário ponderar uma memória negada ou mesmo distorcida por dimensões históricas hegemônicas e homogeneizantes. Nesse sentido, a manutenção da cultura popular, bem como da preservação da tradição afro-brasileira por meio da dança, se estabelece como uma postura de resistência e de valorização da diferença. Enquanto ação humana que apresenta componentes simbólicos, a dança tem a capacidade de trabalhar o corpo como meio para revigorar um conjunto de valores referenciados pela solidariedade, justiça, equidade e pelo respeito às diferenças, especialmente quando considerada em sua tradição afro-brasileira. O trabalho de compreensão da cultura afro-brasileira desenvolvido pelo Grupo de Dança Cristal se efetiva por meio da interpretação de uma herança étnica de caráter dinâmico, ou seja, reinterpretada ao longo do tempo, e que se concilia com a realidade vivida pelos membros do grupo. A sua ação social, iniciada junto ao movimento negro e assegurada por políticas públicas de fomento à cultura e à arte, estabelece um modo de educação não formal que possibilita a instituição de processos educacionais de formação e manutenção de uma etnia e consolida um projeto de sociedade intercultural que caminha na contramão da hegemonia.

\section{THE AFRICAN-BRAZILIAN DANCE IN LONDRINA - PARANÁ}

\begin{abstract}
Based in a problematic context punctuated by the need for studies to explore and know ethnic-racial diversity present in throughout the country, this research aimed to analyze the significance of dance manifestations of Afro-Brazilian culture present in the Grupo de Dança


Cristal [Cristal Dance Group], from Londrina - Paraná. This was an exploratory investigation with a qualitative character, which applied semi-structured interviews as a procedure to collect the data. The research concluded that the activities promoted by the Grupo de Dança Cristal [Cristal Dance Group] enable a permanent reconstruction of the Afro-Brazilian culture, in a resistance posture and appreciation of the difference based in a pluralistic and democratic society project

Keywords: Culture. Afro-Brazilian Dance. Dance.

\section{LA DANZA AFROBRASILEÑA EN LONDRINA - PARANÁ}

\section{Resumen}

Con base en un contexto problemático, pautado por la necesidad de estudios que permitan explorar y conocer la diversidad étnico racial presente en las más diversas localidades del país, esta investigación tuvo como objetivo general analizar el significado de las manifestaciones danzantes de la cultura afrobrasileña presente en las producciones del Grupo de Danza Cristal en Londrina - Paraná. Esta fue una investigación exploratoria, de carácter cualitativo que tuvo como procedimiento para la de recogida de datos la entrevista semiestructurada. Se concluyó que las acciones promovidas por el Grupo de Danza Cristal abren la posibilidad de la permanente reconstrucción de la cultura afrobrasileña, en una postura de resistencia y valorización de la diferencia que se apoya en un proyecto de sociedad plural y democrática.

Palabras clave: Cultura. Manifestaciones Afrobrasileñas. Danza.

\section{Referências}

ALMEIDA, I. J. Presença negra em Londrina: história da caminhada de um povo. Londrina: Atrito Art Editorial, 2004.

BARDIN, L. Análise de conteúdo. Lisboa: Edições 70, 1977.

BRASIL. Lei $\mathbf{n}^{\mathbf{0}} \mathbf{1 0 .} 639$ de 9 de janeiro de 2003. Altera a Lei no 9.394, de 20 de dezembro de 1996, que estabelece as diretrizes e bases da educação nacional, para incluir no currículo oficial da Rede de Ensino a obrigatoriedade da temática História e Cultura Afro-Brasileira, e dá outras providências. Disponível em: <https://www.planalto.gov.br/ccivil_03/leis/2003/L10.639.htm>. Acesso em: 17 nov. 2016.

BRASIL. Resolução no. 7, de 31 de março de 2004. Institui as Diretrizes Curriculares Nacionais para os cursos de graduação em Educação Física, em nível superior de graduação plena. Disponível em: <portal.mec.gov.br/cne/arquivos/pdf/ces0704edfisica.pdf>. Acesso em: 17 nov. 2016.

BRASIL. Resolução n ${ }^{0}$. 1, de 30 de maio de 2012. Estabelece Diretrizes Nacionais para a Educação em Direitos Humanos. Disponível em: <portal.mec.gov.br/index.php?option=com_docman\&view=download\&alias=10889-rcp00112\&category_slug=maio-2012-pdf\&Itemid=30192>. Acesso em: 17 nov. 2016.

BRASIL. Base Nacional Comum Curricular: Linguagens. Proposta Preliminar, 2016. Disponível em: <http://basenacionalcomum.mec.gov.br>. Acesso em: 17 nov. 2016. 
CAMARGO, F. M. T; SBORQUIA, S. P. Mapeamento dos grupos de dança em Londrina-Pr. In: ENCONTRO ANUAL DE INICIAÇÃO CIENTÍFICA E ENCONTRO ANUAL DE INICIAÇÃO TECNOLÓGICA E INOVAÇÃO, 2013, 22, 3, Foz do Iguaçu. Anais... Foz do Iguaçu, 2013.

CANCLINI, N. G. Culturas híbridas: estratégias para entrar e sair da modernidade. 3. Ed. São Paulo: Universidade de São Paulo, 2000.

CHAUÍ, M. Conformismo e resistência: aspectos da cultura popular no Brasil. São Paulo: Brasiliense, 1995.

CORSINO, L. N.; CONCEIÇÃO, W. L. Educação física escolar e relações étnico-raciais: subsídios para a implementação das Leis 10.639/03 e 11.645/08. Curitiba: Editora CRV, 2016.

DOMINGUES, P. Movimento Negro Brasileiro: alguns apontamentos históricos. Tempo, Niterói, v. 12, n. 23, p. 100-122, 2007.

DURHAM, E. R. Cultura e ideologia. Revista de Ciências Sociais, Rio de Janeiro, v.27, n.1, p.71-89, 1984.

GEERTZ, C. A interpretação das culturas. Rio de Janeiro: Guanabara Koogan, 1989.

GOMES JÚNIOR, J.; SILVA, G. L.; COSTA, P. A. B. Paraná negro. Curitiba: UFPR/PROEC, 2008.

GONÇALVES, G. Práticas corporais afro-brasileiras em uma realidade quilombola no Paraná: perspectivas de uma ação interventora. 2012. 139 f. Dissertação (Mestrado em Educação Física) - Programa de Pós-Graduação Associado em Educação Física UEM/UEL, Londrina/Maringá, 2012.

GUIMARÃES, A. S. A. Raça e os estudos de relações raciais no Brasil. Novos Estudos, São Paulo, n. 54, p. 147-156, jul. 1999.

GUSMÃO, N. M. M. Antropologia e educação: origens de um diálogo. Caderno Cedes, Campinas, v. 18 n. 43, dec. 1997.

A noção de cultura e seus desafios. In: PRIMEIRO CONGRESSO BRASILEIRO DE ETNOMATEMÁTICA, 2000, São Paulo: SP. Anais... p. 1-12, 2000.

Os filhos da África em Portugal. Lisboa: ICS, 2004.

HALL, S. Da diáspora: identidades e mediações culturais. Belo Horizonte: Editora UFMG, 2003.

IBGE. Pesquisa Nacional por Amostra de Domicílios. Rio de Janeiro, 2007.

LANZA, F.; SOUZA, A. E. P.; MERISSI, L. C.; DINIZ, L. M.. Yá Mukumby: a vida de Vilma Santos de Oliveira. 2. ed. Londrina: EDUEL, 2013. 
LARA, L. M. Corpo, sentido ético-estético e cultura popular. Maringá: Eduem, 2011.

Esporte e lazer em comunidades quilombolas no Paraná: identificando realidades e apontando desafios para a implementação e/ou aprimoramento de políticas públicas. Pensar a Prática, Goiânia, v. 15, n.1, p. 37-51, jan./mar. 2012.

LARA, L. M.; PIMENTEL, G. G. A. (Org.). Políticas públicas de esporte e lazer em comunidades quilombolas no Paraná. Maringá: Eduem, 2013.

LARA, T. A. Humanismo e cultura. Educação e Filosofia. Uberlândia, v. 4, n. 8, jan./jun. 1990.

PAIXÃO, M. L. B. Dança negra brasileira na contemporaneidade: análise das criações coreográficas do balé folclórico da Bahia e do Grupo Grial de Dança. In.: ENCONTRO DE ESTUDOS MULTIDISCIPLINARES EM CULTURA, 5, 2009, Salvador, Anais... Salvador, 2009. Disponível em: <http://www.cult.ufba.br/enecult2009/19452.pdf>. Acesso em: 17 nov. 2016.

PANTA, M. A. S. Segregação geográfica, desigualdades raciais e migrações: Londrina como destino de fluxos migratórios mineiros e nordestinos (1940-1980). In: SILVA, M. N.; PANTA, M. A. S. (Org.). Território e segregação urbana: 'o lugar' da população negra na cidade. Londrina: EDUEL, 2014. p. 37-66.

SANCHES GAMBOA, S. (Org.). Pesquisa educacional: quantidade-qualidade. 3. ed. São Paulo: Cortez, 2000.

SANTOS, I. F. dos. Corpo e ancestralidade: uma proposta pluricultural de dança-arteeducação. Salvador: EDUFBA, 2002.

SILVA, M. N. População negra: uma presença invisível em Londrina. In: GOUVEIA, E. H.; BALTAR, R.; BERNARDO, T. (Org.). Ciências Sociais na atualidade: temáticas contemporâneas. São Paulo: EDUC, 2011, p. 305-322.

SILVA, M. N. Alguns aspectos da trajetória dos negros na região metropolitana de Londrina. In: SILVA, M. N.; PANTA, M. (Org.). Território e segregação urbana: o lugar da população negra na cidade. Londrina: UEL, 2014, p. 17-36.

SILVA, M. N.; PACHECO, J. Q. (Org.). Dona Vilma: cultura negra como expressão de luta e vida. Londrina: UEL, 2014.

SOUZA, J. H.; SBORQUIA, S. P. Representações da dança afrodescendentes no jornal Folha de Londrina. In: ENCONTRO ANUAL DE INICIAÇÃO CIENTÍFICA, 23, 2014, Londrina. Anais... Londrina, 2014.

TRIVIÑOS, A. M. Introdução à Pesquisa em Ciências Sociais: a pesquisa qualitativa em educação. São Paulo: Atlas, 1997.

TURINO, C. Pontos de cultura: o Brasil de baixo para cima. São Paulo: Ed. Anita Garibaldi, 2010 . 
Recebido em: 23/06/2016

Revisado em: 26/09/2016

Aprovado em: 17/04/2017

Endereço para correspondência:

silviapavesi@uel.br

Silvia Pavesi Sborquia

Universidade Estadual de Londrina

Rodovia Celso Garcia Cid, Km 380, s/n

Campus Universitário

Londrina - PR, 86057-970 